
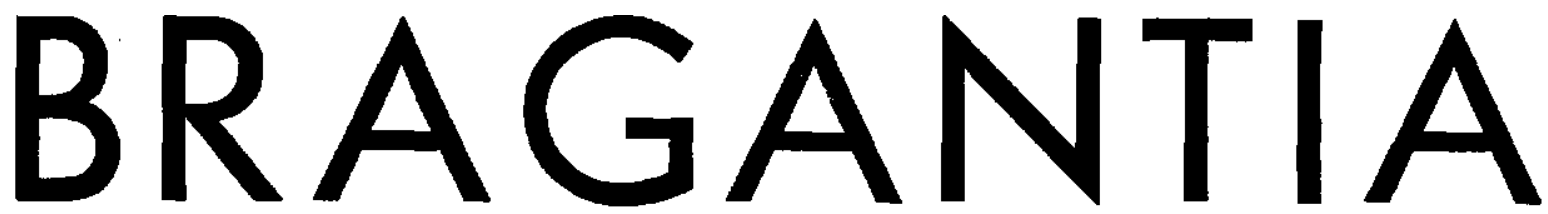

Boletim Técnico do Instituto Agronômico do Estado de São Paulo

Vol. 16

Campinas, outubro de 1957

N. ${ }^{0} 10$

\title{
VARIEDADES DE CAVALOS DE VIDEIRA E SUA MELHOR EPOCA DE ENRAIZAMENTO (*)
}

WILSON CORRÊA RIBAS, engenheiro-agrônomo, Estação Experimental de São Roque e ARmando Conagin, engenheiro-agrônomo, Seção de Técnica Experimental, Instituto Agronômico

\section{R E S U M O}

A indicação prática de que as melhores épocas para plantio de formaçāo de vinhedo no Estado de São Paulo eram os meses de junho, julho e agôsto, se baseavam em observações locais. No entanto, o atual progresso da viticultura paulista estava exigindo que se comprovassem experimentalmente essas informações. Por êste trabalho se verifícou ser possivel a plantação, para formação de vinhedos em são Paulo, desde meados de junho a meados de setembro. Verificou-se também que, desde que seja possível, será melhor plantar os bacelos em junho, julho e agôsto. Conseguiu-se ainda estabelecer mais nitidamente a preferência das variedades de bacelos estudadas com referência às suas melhores épocas de plantação. Verificou-se, também, cosresponder à plantação nesses meses a ccorrência de melhor pagamento e formação de vegetação mais sadia e vigorosa, o que, indubitàvelmante, deverá influir na formação de vinhedos mais homogêneos e de maior produção.

\section{1 - INTRODUÇ̃̃O}

A crescente importância econômica alcançada pelo desenvolvimento da viticultura paulista tem despertado o interêsse de numerosos viti-vinicultores para a adoção de práticas racionais, que venham de encontro à solução de seus numerosos problemas.

Dentre as mais generalizadas dessas práticas, em São Paulo destaca-se a da plantação de bacelos de videiras de variedades e híbridos americanos, para servirem de cavalo a outras variedades americanas, ou viníferas, de características comerciais procuradas. Esse sistema de cultivar a videira, criado depois do advento da filoxera, possibilitou não sòmente a continuação da viticultura mundial, mas também teve o grande mérito de ampliar os seus horizontes, permitindo que se aproveitassem numerosos solos, antes considerados imprestáveis para a exploração da viticultura. $O$ seu aparecimento trouxe, no entanto, a criação de numerosos problemas,

(*) Recebido para publicação em 25 de outubro de 1956. 
tais como os de enxertia, afinidade entre cavalo e garfo, grau de adaptabilidade do cavalo ao solo, melhor época de plantio dos bacelos, e tantos outros cuja solução preocupa os estudiosos do assunto.

A época de plantio dos bacelos e a escolha da variedade a plantar assumem uma importância excepcional, dentro das nossas condições climáticas, pois dependem de um clima onde a temperatura média dos meses de maio a agôsto é menor que a temperatura média anual e onde as chuvas de maio a setembro são escassas e raras. Essas condições, tão favoráveis no sentido de permitirem um completo repouso vegetativo dos cavalos e dos parreirais já estabelecidos, são um enorme empecilho a quantos desejam formar novos vinhedos. A falta de chuvas nessa ocasião e as naturais dificuldades de se proceder à irrigação dos bacelos plantados, são os responsáveis pelos prejuízos ocasionados à formação dos vinhedos, provocando o aparecimento de numerosas falhas que retardam e encarecem a sua formação.

Procurando encontrar, dentro do período de tempo recomendável, épocas e variedades mais favoráveis à formação dos vinhedos paulistas, organizou-se na Estação Experimental de São Roque, um ensaio de Época de Plantio e Variedades de Porta-enxêrto de Videira, cuja condução e resultados são o objeto do presente trabalho.

\section{2 - MATERIAL E MÉTODOS}

Êste experimento foi plantado em quadrado latino 6 x 6 com canteiros subdivididos, as épocas constituindo os canteiros principais e as seis variedades de porta-enxêrtos sendo distribuídas nos subcanteiros. Os canteiros constaram de 6 linhas, espaçadas a $50 \mathrm{~cm}$, em cada uma delas sendo plantados 10 bacelos, havendo espaçamento de $20 \mathrm{~cm}$ entre cada um dos porta-enxertos.

A experiência foi instalada a pleno sol, dentro das condições impostas à grande cultura, em solo de formação arqueana, do tipo massapê, que abrange uma área onde a viticultura é intensa no Município.

Êsse tipo de solo é caracterìsticamente profundo e fresco, relativamente rico em potássio e azôto, pobre em fósforo e cálcio, variando o seu $\mathrm{pH}$ de 5 a 6 (7).

Segundo Setzer (6), o clima de São Roque, onde foi realizada a experiência, é o temperado de inverno menos sêco. Sua extensão no Estado de São Paulo abrange $20.400 \mathrm{~km} 2$ ou aproximadamente $8 \%$ de sua área total. A sua temperatura média anual é inferior a $22^{\circ} \mathrm{C}$, apresentando a de seu mês mais frio média inferior a $18^{\circ} \mathrm{C}$, e amplitude anual superior a $6^{\circ} \mathrm{C}$. A sua pluviosidade é muito intensa durante o verão e pequena no inverno, onde as médias dos meses mais sêcos estão entre 30 e $60 \mathrm{~mm}$ de chuvas. É sujeito a 
geadas e fortes chuvas de pedras. Apresenta grande luminosidade e ausência quase completa de nevoeiros durante todo o ano.

Os bacelos utilizados foram sempre retirados dos mesmos viveiros e sempre que possível do mesmo clone. Tinham no mínimo cinco gemas por estaca, das quais descascamos pelo menos três da base (8), na ocasião de plantar. A sua colheita precedeu o plantio de um a dois dias. Não adotamos a técnica de colhêr os bacelos 15 a 20 dias antes do plantio, estratificando-os em areia antes de serem plantados, porque nossas observações anteriores não recomendavam essa prática.

As estacas tinham um comprimento que nunca ultrapassou $40 \mathrm{~cm}$ e $6-9 \mathrm{~mm}$ de diâmetrọ. Foram plantadas verticalmente, ficando fora da terra sòmente as duas gemas superiores, não descascadas. As estacas plantadas estavam completamente sadias, motivo porque se dispensou a desinfecção contra doenças e pragas.

Para a avaliação estatística da influência das épocas de plantio sôbre o desenvolvimento dos cavalos, mediu-se, em tôdas as variedades, o diâmetro dos porta-enxertos à altura do solo, por ocasião do plantio (quadro 1), e ainda um ano depois, quando também se fizeram outras observações sôbre a incidência de doenças e pragas, o desenvolvimento da folhagem e das raízes apresentadas pelas plantas, depois de cuidadosamente arrancadas.

Como complemento às observações feitas sôbre o diâmetro, em cada época e para cada variedade, determinou-se também a porcentagem de plantas classificadas em três categorias, com relação ao vigor apresentado: fortes, médias e fracas, o que se pode ver no quadro 2.

$\mathrm{Na}$ escolha das épocas para plantio procuramos abranger o maior período de tempo possível, para a plantação de bacelos. Desde meados de maio até meados de outubro foram feitas plantações, espaçadas de um mês mais ou menos uma da outra, perfazendo o total de seis.

Por ocasião da retirada dos bacelos das plantas matrizes, em cada época foram feitas observações sôbre o grau de lenhificação, o estado de repouso, o vigor e a ocorrência de doenças ou pragas sendo escolhidos bacelos sòmente daquelas que se apresentavam bem sadias.

Foram dadas notas para vigor, cujos valores aparecem no quadro 1, e têm a seguinte significação: 1-2 péssimo, 3-4 mau, 5-6 regular, 7-8 bom, 9-10 ótimo. A suscetibilidade dessas plantas com referência à antracnose e peronóspora foi também avaliada por pontos, com a seguinte significação: 1-2, muito suscetivel, $3-4$ suscetível, 5-6 regular, 7-8 resistente, 9-10 muito resistente. 
Quadro 1.-Ensaio de variedades de cavalo de videira e a sua melhor época de enraizamento. Resumo dos caracteristicos vegetativos mais importantes do material de onde provieram os cavalos (*)

\begin{tabular}{|c|c|c|c|c|c|c|c|c|}
\hline \multirow[t]{2}{*}{ Variedades } & Êpocas & Lenhifiçção & Renouso & Vigor & Gernas & $\begin{array}{l}\text { rompri- } \\
\text { melto } \\
\text { médio }\end{array}$ & $\begin{array}{l}\text { Antrac } \\
\text { nose }\end{array}$ & $\begin{array}{c}\text { Peroniss. } \\
\text { pora }\end{array}$ \\
\hline & & & & pontos & $m . "$ & $\mathrm{~cm}$ & pontos & pontos \\
\hline \multirow{6}{*}{$\begin{array}{l}\text { Rupestris } \\
\text { du Lot }\end{array}$} & $15-5$ & Bem arliant. & Jeem iniciarlo & 10 & 8 a 9 & 39 & 7 & 8 \\
\hline & $17-6$ & Completa & Completo & 10 & 6 a 7 & 39 & 10 & 10 \\
\hline & $16-7$ & Completa & Completo & 10 & 8 a 9 & 36 & 10 & 10 \\
\hline & $14-8$ & Completa & Cesmpleto & 10 & 8 a 9 & 35 & 10 & 10 \\
\hline & $17-9$ & Completa & Inicio brot. & 10 & 7 a 8 & 38 & 7 & 8 \\
\hline & $15-10$ & Completa & Rem tivutado & 10 & 6 a 7 & 35 & 7 & 8 \\
\hline Riparia $x$ & $15-5$ & Completa & Inúcio & 10 & 5 a 6 & 40 & 9 & 8 \\
\hline \multirow{5}{*}{ Rup. 101-14 } & $17-6$ & Completa & Completes & 10 & 5 a 6 & 43 & 70 & 10 \\
\hline & $16-7$ & Completa & Completo & 10 & 6 a 7 & 34 & 10 & 10 \\
\hline & $14-8$ & Completa & Completo & 10 & 5 a 6 & 40 & 10 & 10 \\
\hline & $17-9$ & Completa & Inicio brot. & 10 & 6 a 7 & 37 & 9 & 8 \\
\hline & $15-10$ & Completa & Bem brotado & 10 & 6 a 7 & 39 & 9 & 8 \\
\hline \multirow[t]{6}{*}{ Golia } & $15-5$ & Bern adiant." & Bem iniciado & 7 & 6 а 7 & 34 & 8 & 8 \\
\hline & $17-6$ & Bem adiant.a & Mto. b/ inic. & 8 & 6 a 7 & 38 & 8 & 9 \\
\hline & $16-7$ & Bem adiant." & Completo & 8 & 5 a 6 & 35 & 7 & 10 \\
\hline & $14-8$ & Bem adiant.a & Mto. b/ inic. & 8 & 6 a 7 & 37 & 8 & 9 \\
\hline & $17-9$ & Completa & Completo & 8 & 6 a 7 & 37 & 8 & 8 \\
\hline & $15-10$ & Completa & Ben brotado & 8 & 7 a 8 & 38 & 8 & 8 \\
\hline \multirow[t]{6}{*}{ Kobber: 5 BВ } & $15-5$ & Bem atiant." & Bem iriciato & 8 & 5 a 6 & 54 & 10 & 10 \\
\hline & $17-6$ & Iniciada & Completo & 7 & 5 a 6 & 44 & 8 & 8 \\
\hline & $16-7$ & Iniciarla & Complets & 7 & 5 a 6 & 40 & 8 & 8 \\
\hline & $14-8$ & Injeiada & Completo & 7 & 6 a 7 & 39 & $x$ & 8 \\
\hline & $17-9$ & Comp?eta & Inicio brot. & 9 & 6 a 7 & 38 & 10 & 10 \\
\hline & $15-10$ & Completa & Bem brotado & 9 & $5: 6$ & 38 & 10 & 10 \\
\hline Mourv. $x$ & $15-5$ & Completa & Bem iniciado & 9 & 7 a 8 & 47 & 9 & 8 \\
\hline \multirow[t]{5}{*}{ Ruj, 1202} & $17-6$ & Complesa & Bem iniciado & 9 & 7 a 8 & 37 & 7 & 8 \\
\hline & $16-7$ & Completa & Berl iniciado & 9 & 6 a 7 & 35 & 7 & 8 \\
\hline & $3 \frac{4}{x}-8$ & Completa & Completo & 9 & 7 a 8 & 38 & $\tau$ & $x$ \\
\hline & $17-9$ & Completa & Início brot. & 9 & 7 a 8 & 36 & 9 & 8 \\
\hline & $15-10$ & Completa & Pen brotado & 10 & $7 \mathrm{a} 8$ & 36 & 8 & 9 \\
\hline Aramon $x$ & $15-5$ & Bem adiant.a & Bem iniciato & 8 & 9 a 10 & 40 & 6 & 8 \\
\hline Rup. Ganzin & $17-6$ & Bem adiant.a & Bem iniciado & 8 & 6 a 7 & 35 & 6 & $s$ \\
\hline \multirow[t]{4}{*}{ N. 01} & $16-7$ & Bem adiant.a & Mi.o. b/ inic. & 8 & 5 a 6 & 34 & 6 & 8 \\
\hline & $14-8$ & Bem adiant.a & Mto. b/ inic. & 8 & 6 a 7 & $3 i$ & 6 & 8 \\
\hline & $17-9$ & Completa & Inicio brot. & 8 & 7 a 8 & 37 & 6 & 8 \\
\hline & $15-10$ & Completa & Bem brotado & 8 & 6 a 7 & 35 & 6 & 8 \\
\hline
\end{tabular}

(*) Para o vigor e as moléstias foram dadis notas entre 1 e 10 representando as notas mais alta maior vigor ou menor suscetibilidade às moléstias.

Dentro das épocas estudadas, naturalmente deverá haver pelo menos uma que seja a melhor para uma dada variedade de bacelo. Da adoção da época apropriada dependerá a formação de um vinhedo homogêneo e sem falhas, de produção econổmica, que possa recompensar os esforços e as despesas feitas pelo viticultor.

\section{1 - CAVALOS ESTUdAdOS}

Rupestris du Lot - Dos cavalos utilizados em viticultura é êste um dos mais antigos. Apesar de ser considerado por muitos como o "rei" (3) dos porta-enxertos, encontra também numerosos inimigos, que procuram limitar o seu emprêgo, apontando vários 
inconvenientes. Acreditamos ter sido êste um dos cavalos há mais tempo introduzido no Brasil. O material utilizado nesta experiência foi obtido de um viveiro existente na Estação Experimental de São Roque, originário, provàvelmente, de bacelos obtidos no Instituto Agronômico, em 1928.

QUADRo 2.-Ensaio de variedades de cavalo de videira e a sua melhor época de enraizamento. Resumo dos característicos vegetativos mais importantes apresentados pelos cavalos no decorrer do seu desenvolvinento vegetativo (*)

\begin{tabular}{|c|c|c|c|c|c|c|c|c|c|c|c|c|}
\hline \multirow{2}{*}{ Epccas } & \multirow{2}{*}{$\begin{array}{l}\text { Varie- } \\
\text { dades }\end{array}$} & \multicolumn{2}{|c|}{$\begin{array}{c}\text { Gressura } \\
\text { média }\end{array}$} & \multirow{2}{*}{$\begin{array}{c}\text { Pega- } \\
\text { mento } \\
\text { total }\end{array}$} & \multicolumn{3}{|c|}{ Grupos de baceles } & \multirow{2}{*}{ Vigor } & \multirow{2}{*}{$\begin{array}{l}\text { An- } \\
\text { trac- } \\
\text { nose }\end{array}$} & \multirow{2}{*}{$\begin{array}{l}\text { Pero- } \\
\text { nós- } \\
\text { pora }\end{array}$} & \multirow{2}{*}{ Folhagem } & \multirow{2}{*}{ Raízes } \\
\hline & & 1952 & 1953 & & Fortes & Mésios & Fracos & & & & & \\
\hline & & $m \boldsymbol{m}$ & $m m$ & $\%$ & $\%$ & $\%$ & ro & pontos & pontos & Irontos & & \\
\hline \multirow[t]{6}{*}{$15-5$} & RL & 5,4 & 10,5 & 62 & 62 & 14 & 24 & 7,3 & 7,0 & 9,6 & Bastante & Poucas \\
\hline & $\mathbf{M} \times \mathbf{R}$ & 5,9 & 8,9 & 78 & $\notin 4$ & 23 & 13 & 3,5 & 6,5 & 10,0 & Regular & Bem poucas \\
\hline & & 3,6 & 9,2 & 38 & 44 & 30 & 26 & 4,0 & 7,1 & 10,0 & Bem pouca & Bem poucat; \\
\hline & & 6,3 & 9,1 & 52 & 71 & 13 & 16 & 6,1 & 7,1 & 10,0 & Bastante & Bem poucas \\
\hline & $\mathbf{A} \times \mathbf{R G}$ & 5,6 & 8,9 & 70 & 74 & 17 & 9 & 3,5 & 6,3 & 9,6 & Regular & Regular \\
\hline & $\mathbf{R} \times \mathbf{R}$ & $\bar{i}, 3$ & 10,0 & 63 & 53 & 29 & 18 & 6,8 & 5,5 & 10,0 & Bastante & Poucas \\
\hline \multirow[t]{6}{*}{$17-6$} & $R L$ & 5,2 & 12,2 & 92 & 82 & 11 & 7 & 9,5 & 7,0 & 10,0 & Bastante & Bastante \\
\hline & $M \times R$ & 4.9 & 9,1 & 82 & 65 & 23 & 12 & 6,8 & 6,6 & 10,0 & Bastante & Regular \\
\hline & & $5, \tilde{0}$ & 9,7 & 62 & 53 & 22 & 19 & 5.6 & 6,0 & 10,0 & Regular & Bem poucas \\
\hline & & 6,2 & 8,6 & 77 & 69 & 22 & 9 & 6,8 & 7,1 & 10,0 & Bastante & Regular \\
\hline & $A \times R G$ & 5,2 & 9,2 & 82 & 78 & 12 & 10 & 7,9 & 7,1 & 10,0 & Bastante & Regular \\
\hline & $\mathbf{R} \times \mathbf{R}$ & 5,8 & 8,9 & 80 & 73 & 19 & 8 & 7,3 & 6,0 & 9,6 & Bastante & Regular \\
\hline \multirow[t]{5}{*}{$16-7$} & & 5,0 & 11,3 & 75 & 64 & 20 & 16 & 8,1 & 6,1 & 10,0 & Bastante & Bastante \\
\hline & $M \times R$ & 5,4 & 9,7 & 70 & 69 & 14 & 17 & 6,1 & 6,3 & 10,0 & Regular & Regr. a poucas \\
\hline & & 5,8 & 9,1 & 62 & 35 & 41 & 94 & 4,0 & 7,3 & 10,0 & Bem pouca & Bem pouess \\
\hline & & 5,6 & 7,1 & 70 & 48 & 26 & 96 & 4,3 & 7,5 & 10,0 & Bastante & Bem poucas \\
\hline & $\begin{array}{l}A \times R_{1} \\
R \times B\end{array}$ & $\begin{array}{l}0.0 \\
5,8\end{array}$ & $\begin{array}{l}8,9 \\
8,9\end{array}$ & $7 \pi$ & 60 & 12 & 19 & 6,3 & 7,1 & 10,0 & Regular & Poucas \\
\hline \multirow{6}{*}{$14-8$} & & & & & & & & 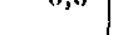 & & 10,0 & Bastante & Regula.r \\
\hline & RL & 5,2 & 9.8 & 52 & 61 & 19 & 20 & 5,1 & 5,6 & 10,0 & Reg. a bast. & Poucas \\
\hline & $\mathbf{M} \times \mathbf{R}$ & 5,7 & 8,5 & 85 & 61 & 25 & 14 & 6.1 & 6,5 & 10,0 & Re: & Bem pe. a reg. \\
\hline & & $5, x$ & 8,7 & as & 37 & 37 & 26 & 4,6 & 6,1 & 10,0 & Bem pouca & Bem poucas \\
\hline & $A \times R G$ & 5,6 & 8.4 & 60 & $\begin{array}{l}49 \\
58\end{array}$ & 31 & 24 & $\begin{array}{l}4,3 \\
5,1\end{array}$ & $\begin{array}{l}n, 0 \\
6.8\end{array}$ & 100 & $\begin{array}{l}\text { Reguar } \\
\text { Regular }\end{array}$ & $\begin{array}{l}\text { Pouca a rex. } \\
\text { Reg, a bem nc. }\end{array}$ \\
\hline & $R \times R$ & 5.9 & 9,2 & 90 & 69 & 22 & 9 & 8,3 & 5,8 & 10,0 & Bastante & Bastante \\
\hline \multirow[t]{6}{*}{$17-9$} & RL & 6,0 & 10,3 & 75 & 75 & 18 & 7 & 8,1 & 5,8 & 10,0 & Bastante & Bastante \\
\hline & $M \times R$ & 5,6 & 8,1 & 78 & 53 & 28 & 19 & 5,3 & 6,8 & 10,0 & Bem pouca & Bem poucas \\
\hline & & 6,5 & 8,7 & 60 & 64 & 25 & 11 & 6.0 & 6,6 & 10,0 & Pouca & Bem poucas \\
\hline & & 5,0 & 6,9 & 53 & 47 & 28 & 25 & 5,1 & 7,1 & 10,0 & Bastante & Regular \\
\hline & $A \times R G$ & 5.3 & 7,1 & 52 & 48 & 26 & 26 & 3,5 & 7,3 & 10,0 & Bem pouca & Bem poucas \\
\hline & $\mathbf{R} \times \mathbf{R}$ & 5,1 & 7,9 & 77 & 43 & 35 & 22 & 5,1 & 5,6 & 10,0 & Reg. a bast. & Regular \\
\hline \multirow[t]{6}{*}{$15-10$} & RI. & 5,5 & 8,9 & 55 & 64 & 12 & 24 & $5, \AA$ & 6,0 & 10,0 & Bastante & Regular \\
\hline & $\mathrm{M} \times \mathrm{R}$ & 5.4 & 7,2 & 57 & 24 & 41 & 35 & 3,3 & 6,6 & 10,0 & Pouca & Bem poucas \\
\hline & (x) & 5,6 & $\overline{7}, 0$ & 31 & 26 & 32 & 42 & 2,5 & 6,6 & 10,0 & Bem pouca & Bem poucas \\
\hline & & 4,7 & 6,4 & 22 & 23 & 46 & 31 & 2.3 & 7,0 & 10,0 & Bem pouca & Bem poucas \\
\hline & $A \times R G$ & 4.9 & 6,3 & 52 & 26 & 32 & 42 & 3,0 & 7,1 & 10,0 & Bem pouca & Bem poucas \\
\hline & $R \times R$ & 5,1 & 7,8 & 52 & 26 & 32 & 42 & 4,3 & 5,8 & 10,0 & Regular & Poucas \\
\hline
\end{tabular}

(*) Para vigor e moléstias, as mesmas convenções do quadro 1 foram adotadas.

Há muitos que procuram limitar o seu uso, apontando-lhe os seguintes defeitos: a) o exagerado vigor que imprime aos enxertos, nas primaveras úmidas e frias, provocando o abôrto das flôres; b) a sua particular receptividade ao "roncêt", à podridão radicular e à clorose; c) a sua condicional resistência às sêcas, tardia lenhi- 
ficação e o atraso que provoca na nutrição dos frutos; d) é acusado ainda de proporcionar aumento da quantidade em detrimento da qualidade dos frutos das videiras nêle enxertadas; e) a facilidade com que rebrota abaixo do enxêrto, provocando todos os anos necessidade de intensa desbrota.

Nossa observação, feita sôbre um grande número de enxertos de diferentes variedades sôbre êste cavalo, nem sempre nos autoriza a aceitar a maior parte dos defeitos acima apontados. Pelo exame do quadro 1, pode-se verificar que o porta-enxêrto Rupestris du Lot já se encontrava bem lenhificado e em repouso bem adiantado, quando da sua primeira época de plantação. Manteve-se em completo repouso de junho a agôsto, iniciando a vegetação em setembro. Em outro trabalho, ainda não concluído, estamos procurando verificar detalhadamente tôdas as características de afinidade dêste porta-enxêrto e de outros, com numerosas variedades.

E um dos cavalos mais vigorosos que possuimos em nossa coleção, suas estacas apresentando de 35 a $40 \mathrm{~cm}$ de comprimento e 6 a 9 gemas. Pouco suscetível à antracnose e peronóspora. Apresenta, de uma maneira geral, boa afinidade com as diversas varielades de Seibel, Pirovano 4, Valdiguiè, Müller Thurgau, Niágara Branca e Rosada, Moscatel de Hamburgo, Golden Queen e Alphonse Lavallée. Adapta-se bem aos nossos solos, devendo-se, no entanto, evitar as terras muito férteis e frescas, principalmente se úmidas e planas. Não serve para videiras que exigem poda pobre. Pode vegetar em solos que apresentam em sua composição até $30 \%$ de calcário, condição que pouco nos interessa devido à natureza em geral pobre de cálcio, da maioria de nossos solos.

Riparia x Rupestris 101-14 - Êste é um cavalo obtido artificialmente por Millardet e de Grasset (4), em 1882. Predominam nêle os característicos do Riparia. $\hat{\mathrm{E}}$ muito bom, sendo paulatinamente preferido pelos que o conhecem. Permite aos enxertos boas produções qualitativas e quantitativas de-frutos. $O$ viveiro que forneceu o material para a experiência foi plantado com bacelos obtidos provàvelmente em 1939, de Pepinières Richter, Montpellier, França.

É também bastante vigoroso, comparável ao Rupestris du Lot. Suas estacas, com $40 \mathrm{~cm}$ de comprimento têm de 6 a 7 gemas. Lenhifica-se completamente desde maio, em nosso clima, sendo, portanto, um dos cavalos de lenhificação mais precoce entre nós. E suscetível ao ataque da peronóspora tanto como o Rupestris, porém mais resistente que aquêle e outros à antracnose, talvez devido à sua maior precocidade de lenhificação. . Apresenta boa afinidade de enxertia com S. 6905, Müller Thurgau, S.V. 5276, S. 10096, S. 7053, Golden Queen, P. 65 ou Itália, Niágara Branca e Rosada, P. 87 ou Diamante Negro, Valdiguié, Pirovano 4 e Moscatel de Hamburgo. 
Adapta-se bem à maioria dos nossos solos, preferindo os frescos e profundos, mesmo pesados (5). É mais indicado que o Rupestris du Lot para os terrenos planos, algo argilosos. Serve também para os terrenos calcários.

Golia - Êste cavalo é um híbrido complexo de Pirovano (5). Foi obtido pelo cruzamento de uma Vinífera $x$ Riparia com pólen de Rupestris du Lot tratado eletromagnèticamente. Não é ainda um porta-enxêrto bem difundido entre nós, não sendo mesmo muito conhecido. especialmente indicado para videiras que preferem poda longa. Seus enxertos soldam-se muito bem. Segundo Pirovano (5) apresenta boa afinidade com os seus híbridos. Entre nós não houve ainda tempo suficiente para observar a sua afinidade com as nossas variedades mais comuns.

Dos cavalos estudados neste ensaio é um dos menos vigorosos. $\hat{\mathbf{E}}$ de tardia lenhificação. Suas estacas, com $38 \mathrm{~cm}$ possuem de 6 a 8 gemas; foram retiradas de um viveiro organizado com material oriundo do Instituto Agronômico em 1950. Bem suscetível à antracnose e mais ainda à peronóspora. Suas raízes são carnosas e de ângulo geotrópico menor que o Rupestris du Lot, fazendo com que elas penetrem quase verticalmente no solo onde, principalmente nos nossos, vegetam bem. Com um ano encontram-se indivíduos que apresentam de 8 a $10 \mathrm{~mm}$ de diâmetro. Recomenda-se para terras pobres. Suporta até $40 \%$ de calcário no solo.

Kobber 5 BB - Das seleções feitas por Kobber (3), para cavalos de videira, foi uma das mais felizes. Não é também um porta-enxêrto bem difundido e conhecido entre os nossos viticultores, apesar de ter sido introduzido na Estação Experimental de São Roque desde 1939, conforme remessa de bacelos feita por Pepinières Teleki - Hungria. Apresenta pouca afinidade com as variedades de videiras St. Jeannet, Gros Vert, Perla Di Csaba, Panse Precoce, Delizia Di Vaprio, Baresana, Pirovano 4, S. 10.096, S. 7.053, Valdiguiè, S. 5.213, P. 65 Itália, Niágara Rosada, Golden Queen, P. 87 Diamante Negro, Alphonse Lavallée e outras.

É de tardia lenhificação entre nós. Contudo, já na primeira época se apresentou em início de repouso vegetativo. Seu vigor é comparável ao do Golia, sendo menos vigoroso que os outros. Seus entre-nós são longos. Estacas até com $54 \mathrm{~cm}$, apresentam de 5 a 6 gemas. Pouco suscetível à antracnose e peronóspora. Adapta-se aos nossos solos mas é especialmente indicado para os terrenos áridos, mesmo calcários.

Mourvedre x Rupestris 1202 - Supõe-se que seja uma combinação da Mourvedre com o Rupestris du Lot. Não é um porta-enxêrto resistente à filoxera (3) sendo, portanto, pouco recomendável o seu uso. Retarda a maturação e facilita o abôrto das flôres. É de lenhificação precoce, como se pode observar no quadro 1, mas re- 
pousa muito pouco, encontrando-se quase durante todo o ano em vegetação. É de vigor médio. Suas estacas de $37 \mathrm{~cm}$ têm em média 7 a 8 gemas. Suscetível ao ataque da antracnose e peronóspora. Não é um porta-enxêrto muito utilizado entre nós, sendo no entanto conhecido na Estação Experimental de São Roque desde 1939, quando foi introduzido com o Kobber 5 BB. Sua afinidade para com um grande número de variedades é pequena, podendo no entanto, ser considerada boa para a S. 6.905, S. 10.096, Valdiguié, Müller Thurgau e regular para a S.V. 5.276 e Niágaras. Vegeta em nossos solos, mas sòmente poderá ser indicado com vantagem para solos isentos de filoxera, profundos, algo úmidos e calcários (3).

Aramon x Rupestris Ganzin $n^{\circ} 1$ - Êste cavalo foi criado para resistir melhor aos terrenos calcários e evitar a pletora (5). Não é quase conhecido pelos nossos viticultores, sendo pouco empregado. $\mathrm{Na}$ Estação Experimental de São Roque êle é cultivado em viveiro desde 1939, onde foi introduzido com material procedente de Pepinières Teleki - Hungria. É de lenhificação muito tardia e pràticamente não repousa, em nossas condições.

Seu vigor é comparável ao do Golia, apresentando estacas com $35 \mathrm{~cm}$ de comprimento com 7 a 8 gemas. Bem suscetível à antracnose e menos à peronóspora. É bem resistente à filoxera e à clorose. Especialmente indicado para videiras de poda longa e quando se pretende retardar a maturação dos frutos (4). Sua afinidade é boa para Müller Thurgau e Alphonse Lavallée, sendo regular para S. 6.905, P. 65 Itália, Niágara Rosada e Moscatel de Hamburgo. Adapta-se aos nossos solos mas é especialmente indicado para terrenos compactos, frescos e calcários (3).

\section{3 - RESULTADOS}

Com auxílio de um pálmer foi determinado o diâmetro dos bacelos, por ocasião do plantio e um ano após (quadro 2) ; os dados representam as médias dos resultados individuais.

As porcentagens de pegamento total e de grupos de bacelos (fortes, médios e fracos) acham-se no mesmo quadro.

Observações feitas sôbre o vigor apresentado pelos cavalos nas diferentes épocas se encontram no quadro 2 , bem como a incidência de doenças e uma apreciação sôbre a formação das partes aéreas e subterrânea.

\section{4 - ANÁLISE ESTATÍSTICA DOS RESULTADOS}

A análise estatística foi feita para a variável transformada arc sen $V \%$ cavalos mortos, por ser uma variável ligada à distribuição binomial. As médias da variável transformada se encontram no quadro 3. 
QuAdro 3.-Ensaio de variedades de cavalo de videira e a sua melhor época de enraizamento. Médias dos dados arc sen $\sqrt{\% \text { cavalos mortos }}$

\begin{tabular}{l|r|r|r|r|r|r|r}
\hline cavalos & M x R & R. L. & G & K & A x RG & R x R & Médias \\
\hline Maio . . . . . & 37,90 & 43,90 & 56,44 & 48,12 & 25,58 & 34,93 & 41,14 \\
Junho . . . . & 15,00 & 26,47 & 41,94 & 31,90 & 24,00 & 24,72 & 27,33 \\
Julho . . . . & 29,00 & 36,90 & 40,12 & 45,01 & 27,89 & 28,84 & 34,62 \\
Agôsto . . . . & 44,01 & 24,72 & 40,97 & 39,86 & 18,57 & 40,58 & 34,78 \\
Setembro . . . & 31,11 & 30,75 & 39,11 & 45,97 & 25,73 & 47,12 & 36,63 \\
Outubro . . . . & 43,04 & 49,04 & 57,26 & 67,76 & 42,04 & 47,94 & 51,17 \\
\hline Médias . . . . . & 33,34 & 35,29 & 45,97 & 46,43 & 27,30 & 37,35 & \\
\hline
\end{tabular}

A análise da variância dêsses valores encontra-se no quadro 4; houve diferenças altamente significativas entre as épocas, entre cavalos e ainda interação cavalos $x$ épocas. No modêlo matemático QuAdro 4.-Ensaio de variedades de cavalo de videira e a sua melhor época de enraizamento. Análise da variância dos dados arc sen $\sqrt{\% \text { cavalos mortos }}$

\begin{tabular}{|c|c|c|c|c|}
\hline Fonte de Variação & GL & $\begin{array}{l}\text { Soma de } \\
\text { quadrados }\end{array}$ & $\begin{array}{l}\text { Quadrados } \\
\text { médios }\end{array}$ & $\mathbf{F}$ \\
\hline Colunas $\ldots \ldots \ldots \ldots$ & 5 & $.3 .201,8716$ & 640,3743 & $3,13 i^{*}$ \\
\hline Linhas . . . . . . . . . . & $\mathbf{5}$ & $1.863,6439$ & 372,7288 & 1,826 \\
\hline Epocas $\ldots \ldots \ldots$ & 5 & $11.514,7903$ & $2.302,9581$ & $11,282^{* * *}$ \\
\hline frrro (a) $\ldots \ldots \ldots \ldots$ & 20 & $4.082,5291$ & 204,1264 & $\ldots \ldots \ldots$ \\
\hline Total (1) . . . . . . . & 35 & $20.662,8349$ & (5) & $\ldots \ldots \ldots$ \\
\hline Cavalos $\ldots \ldots \ldots$ & 5 & $9.993,5677$ & $1.998,7135$ & $17,03 * * *$ \\
\hline Interaçäo Cav. $x$ épocas $\ldots$ & 25 & $5.904,9096$ & 236,1964 & $2,013^{* *}$ \\
\hline Erro $(b) \ldots \ldots \ldots$ & 150 & $17.595,8440$. & 117,3056 & $\ldots \ldots \ldots$ \\
\hline Total $(2) \ldots \ldots \ldots$ & 215 & $54.157,1562$ & $\ldots$ & $\ldots \ldots \ldots$ \\
\hline
\end{tabular}

da análise da variância as variáveis épocas e cavalos foram consideradas como fixas (2). As diferenças mínimas significativas foram as seguintes (1):

para a comparação de duas épocas, $t \sqrt{\left(2 \mathrm{E}_{\mathrm{a}}\right) / \mathrm{r}} \bar{\beta}=7,024$ para a comparação de dois cavalos quaisquer,

$$
\mathrm{t} \sqrt{2 \mathrm{E}} \overline{\mathrm{E}} / \mathrm{r} \alpha=5 ; 045
$$

para a comparação de dois cavalos plantados na mesma época,

$$
t \sqrt{2} \overline{\mathrm{E}_{\mathrm{b}}} / \mathrm{r}=12,356
$$

para a diferença entre duas épocas em um mesmo cavalo, 


$$
\begin{aligned}
& t^{\prime} \sqrt{2\left[(\hat{\beta}-1) \mathrm{E}_{\mathrm{b}}+\mathrm{E}_{\mathrm{a}}\right] / \overline{\mathrm{r}}}=13,279 \text {, onde } \\
& t^{\prime}=\frac{(\beta-1) \mathrm{E}_{\mathrm{b}} \mathrm{t}_{\mathrm{b}}+\mathrm{E}_{\mathrm{a}} \mathrm{t}_{\mathrm{a}}}{(\beta-1) \mathrm{E}_{\mathrm{b}}+\mathrm{E}_{\mathrm{a}}}=2,004
\end{aligned}
$$

Pelos resultados obtidos a melhor época foi a de meados de junho. A seguir tivemos julho, agôsto e setembro sem diferença estatística entre elas. As piores épocas foram meados de maio e meados de outubro.

Considerando os cavalos como um todo, o cavalo que apresentou a maior porcentagem de pegamento foi o Aramon $\mathrm{x}$ Rupestris Ganzin. A seguir se classificaram o Mourvedre x R 1202, Rupestris du Lot, Rupestris x Riparia, sem diferença estatística entre êles. Os piores foram Golia e Kobber.

Comparações que apresentam ainda interêsse, são as que abrangem a comparação das épocas para um mesmo cavalo.

Para Aramon $x$ Rupestris Ganzin as cinco primeiras épocas foram melhores. Outubro foi estatìsticamente inferior às outras épocas.

Para Rupestris du Lot as melhores épocas foram junho, julho, agôsto e setembro, sem diferença estatística entre elas, sendo piores maio e outubro.

Para Riparia $\mathbf{x}$ Rupestris, as melhores épocas foram maio, junho, julho e agôsto, sem diferença estatística, sendo piores setembro e outubro.

Para Mourvedre x Rupestris 1202, junho foi a melhor época, seguida de julho e setembro. Agôsto apresentou-se pior que setembro, revelando certa discrepância. Maio e outubro foram as épocas menos apropriadas.

Para o cavalo Golia, junho, julho, agôsto e setembro foram melhores que maio e outubro.

Finalmente, para o cavalo Kobber, junho foi a melhor época, sem diferir, porém, de agôsto. Agôsto foi equivalente a julho, setembro e maio. A pior época de tôdas foi, ainda, outubro.

Dos estudos realizados verifica-se que se deve iniciar o plantio dos porta-enxertos de videira a partir de meados de junho, podendo prolongar-se êsse plantio até meados de setembro. Antes de 15 de junho e depois de 15 de setembro não devem ser plantados cavalos. 


\section{5 - CONCLUSõES}

a) O plantio de bacelos porta-enxertos na região vitícola de São Roque no Estado de São Paulo deve ser feito de meados de junho a meados de setembro.

b) Sempre que possível deve-se preferir a época precoce para a plantação dos cavalos.

c) Os cavalos sòmente deverão ser retirados dos viveiros para plantar, quando estiverem com o máximo de reservas nutritivas em seus tecidos, o que deve ocorrer quando estão perfeitamente lenhificados e em repouso vegetativo.

d) O plantio do porta-enxêrto na melhor época condicionou, além de uma maior porcentagem de pegamento, uma porcentagem maior de cavalos de vegetação sadia e vigorosa.

e) Havendo já observações que no Estado de São Paulo, para um certo número de porta-enxertos, as épocas mais apropriadas são junho, julho e agôsto, verifica-se que os resultados dêste experimento vêm, em linha geral, confirmar o que a prática tem já consagrado.

\section{ROOTING DATE FOR GRAPE ROOTSTOCK CUTTINGS}

\section{S U M M A R Y}

The experiment reported in this paper was carried out to determine the mosi appropriate time to root cuttings of six of the most common rootstock varieties of grapes under field conditions in the state of São Paulo. The rootstocks tested were Rupestris du Lot, Riparia x Rupestris 101-14, Golia, Kobber 5BB, Mourvedre x Rupestris 1202, and Aramon x Rupestris Ganzin No. 1. The following rooting dates were compared: mid of May, June, July, August, September, and October.

Cutting of all varieties tested gave good rootstocks when rooted in June, July, and August. Not only was the percentage of established rootstocks higher, but there was also a higher percentage of vigorously growing plants. Cuttings rooted in May, September, and October gave poor results.

The good results obtained in June, July, and August were attributed in great part to the use of cuttings from completely lignified branches that had dormant buds, whereas those used in May were taken from branches still immature, and those for September and October, from matrices that were starting the new vegetative growth.

\section{LITERATURA CITADA}

1. COCHRAN, W. G. \& COX, G. M. Experimental designs. New York, John Wiley \& Sons, Inc., 1950. p. 223-224.

2. KEMPTHORNE, OSCAR. The design and analysis of experiments. New York, John Wiley \& Sons, Inc., 1952. p. 375-376.

3. MOTA, JOAQUIM I. SILVEIRA DA. A enxertia da videira. Rio de Janeiro, Imprensa Nacional, 1946. viii, 120 p.

4. OLIVIERI, OLIVIERO. Vitigni porta. Innesti americani: loro riconoscimento ed attidudini colturali. Milano, Ulrico Hoepli, 1936. vi, 255 p. 
5. PIROVANO, ALBERTO. Uve da tavola. Loro coltivazione... Milano, Premiata scuola tipografica salesiana, 1933. vii, $115 \mathrm{p}$.

6. SETZER, JOSE. Contribuição para o estudo do clima do Estado de São Paulo. São Paulo, Escolas profissionais salesianas, 1946.239 p.

7. Os solos do Estado de São Paulo. Campinas, Instituto agronômico, 1940. 35 p. (Boletim Técnico n. 70)

8. ZAPORTA, M. M. Experiencias correspondentes al año de 1948 sobre enraizamento de porta-enjertos usuales con sangre de Berlandieri. Madirid, Instituto nacional de investigaciones agronomicas, 1949. $48 \mathrm{p}$. (Boletim n. 20) [Original não consultado; extraído de Notícias bibliográficas 9:31] 